\title{
Violencia, cosificación y sexismo discursivo en canciones de banda mexicanas
}

\section{Violence, objectification and discursive sexism in Mexican band songs. A sociopragmatic study}

\author{
María Eugenia Flores Treviño (iD ${ }^{1}$, Julio Hernández Maldonado (iD ${ }^{2}$ \\ ${ }^{1}$ Universidad Autónoma de Nuevo León, Nuevo León, México \\ maria.florestr@uanl.edu.mx \\ ${ }^{2}$ Universidad Autónoma de Nuevo León, Nuevo León, México \\ tuxtenotrian@hotmail.com
}

\section{Resumen}

En este trabajo estudiamos la incidencia que ejerce en México la letra de las canciones de banda, que encierra violencia simbólica sobre cómo cosificar a la mujer y genera imaginarios sexistas. La difusión que de ellas realiza la radio, se constituye en un ejercicio del poder, ya que la popularidad le da a este medio un potencial de circulación mayor que la TV (León, 1989) en la que también se difunden los videos de estas canciones. El presente trabajo ofrece una perspectiva pragmática, sociopragmática y semiótico discursiva sobre cómo se construye un imaginario, un ethos discursivo en el que los jóvenes, principalmente, ven reflejado su deseo de conseguir estatus, poder, mujeres y sobre todo, reconocimiento ante un grupo de iguales, por medio de la letra de cinco canciones, a través de lo contenido en la historia que se desarrolla y en el video que acompaña a cada canción.

Keywords: violencia discursiva; sexismo; canciones mexicanas; sociopragmática.

Recibido: 12/02/2020

Aceptado: 18/05/2020

Conflicto de intereses: Los autores han declarado que no poseen conflicto de intereses.

Copyright: @ C M. E. Flores Treviño, J. Hernández Maldonado. Esta obra está bajo licencia $\underline{\text { Creative Commons }}$ Reconocimiento 4.0.

\begin{abstract}
In this paper we studied the incidence that some folk band song lyrics exert in Mexico, that embodies symbolic violence about how to objectify a woman and thus, generates sexist imageries. The song lyrics spreading made by the radio constitutes a power exercise because popularity gives this means a wider media coverage potential rather than TV (León, 1989) where video songs are released. This current work offers a pragmatic, socio-pragmatic and discursive semiotic perspective about how an image, a discursive ethos is built up through five song lyrics in the story plot development and the video that comes in each song, where youngsters mainly, portrait their desire to get status, power, women and above all, recognition before peers.
\end{abstract}

Palabras clave: discoursive violence; sexism; mexican songs; sociopragmatic. 


\section{Introducción}

La influencia que ejerce en la actualidad el discurso de las canciones promueve además de una dosis de violencia hacia otro ser humano, un hostigamiento masivo sobre la imagen social de la mujer. Aparte, en la letra, la muerte se hace presente no solo como espectáculo, sino como medio para el logro de fines personales perseguidos por los protagonistas de las anécdotas o narraciones contenidas en las letras de esas composiciones. La radio como medio de difusión masiva, ejerce poder. "Su capacidad para crear imágenes auditivas, hace que el medio sea tan visual o más que la propia TV" (León, 1989, p. 139).

Tomamos en consideración las interrogantes: “¿De qué manera los lingüistas y no lingüistas pueden trabajar juntos para explicar mejor los problemas de nuestra sociedad? (Bolívar, 2003, p. 7) para justificar el estudio que se realiza, pues creemos que a través de la exposición de los recursos socio-pragmáticos y discursivos aportamos a la visibilización y la reflexión sobre los usos no éticos del lenguaje y sus recursos. "¿De qué manera desde las diferentes disciplinas podemos intervenir para promover cambios y mantener valores fundamentales de la condición humana?" (Bolívar, 2003, p. 7). Creemos que es posible colaborar desde la interpretación global del discurso, para mostrar los propósitos lingüísticodiscursivos de los autores de estos versos, los cuales, dada la influencia que tienen sobre los jóvenes a nivel nacional y un poco más allá de las fronteras de México con Estados Unidos, expanden estas posturas de poder y motivan a su público ¿por qué no? a construir una perspectiva sobre la vida real en sociedad.

En este trabajo ofrecemos los sustentos teóricos que fundamentan esta aproximación, luego describimos el corpus y la metodología; enseguida exponemos los rasgos del objeto de estudio; presentamos el análisis y la discusión, para luego mostrar los resultados obtenidos y su interpretación. Cerramos con las conclusiones y las perspectivas que se derivan de este primer acercamiento al objeto de estudio.

\subsection{El objeto de estudio}

Para abordar el carácter lírico de la canción, con Bernardelli (2010), quien señala que

La idea de la "lírica moderna" fundamentalmente antidiscursiva y autorreferencial es más bien una leyenda ideológica, un mito teórico-polémico que una realidad; incluso un lírico absoluto como Gottfried Benn alterna el rigor del estilo que nombra y del monologismo abstracto con poesía-retrato, poesía de la cotidianeidad e inventiva (Bernardinelli, citado en Mendoza 2010, p. 2).

La descripción que el autor hace para la poesía de Ponge, nosotros la encontramos útil para puntualizar el tipo de canción que estudiamos en la cual " $\mathrm{La}$ descripción inmanente del objeto deviene una especie de épica o lírica de la singularidad, de la diversidad, de la multiplicidad irreductible en la cual estamos inmersos" (Bernardinelli, citado en Mendoza 2010, p. 7)

Por otra parte, la llamada música de banda tiene una tradición histórica que va desde las bandas itinerantes, hasta las bandas imperiales. Estos grupos musicales han acompañado a la sociedad en grandes acontecimientos, inclusive en las guerras y revoluciones. Astruells las define así:

Etimológicamente, la palabra banda de música significa un conjunto musical formado por instrumentos de viento y percusión. Ahora bien, el término banda ha sido aplicado con anterioridad a distintos tipos de agrupaciones musicales. Por 
ejemplo, en la época del rey Luis XIV se denominaba La Grande Bande al conjunto de sus 24 violines. También en Inglaterra se conoció con el nombre de The King's Private Band a un conjunto formado por 24 flautas. El concepto de bandas que tenemos actualmente es un concepto moderno, formado por oboes, fagotes, flautas, clarinetes, requintos, clarinetes bajos, saxofones sopranos, altos, tenores y barítonos, trompetas, fliscornos, trompas, trombones, bombardinos, tubas y un gran número de instrumentos de percusión (Astruells, 2012).

El texto audiovisual, el video ${ }^{1}$ del cual se acompañan las canciones, encierra en sí mismo su propia significación: por una parte, porta un mensaje dirigido a una audiencia en particular, por otra, mediante el proceso sociocultural permite a dicha audiencia el transformar esos signos vacíos dentro del mensaje -el video musical, en este caso- en símbolos de valor para quienes los reciben. Retomamos la acepción de símbolo, definido por Reig:

Por símbolo entendemos cualquier objeto que representa a otra cosa en virtud de su correspondencia o analogía y las señales que empleamos los humanos para comunicarnos, los símbolos y sus significados las transformamos a través del sonido (lenguaje, música, etc.), el gesto (corporal y ritual) y la imagen (arte, pintura, escultura, escritura...hasta llegar a nuestra elaboradísima iconografía audiovisual moderna) (Reig, 2004, p. 37).

El video musical ha llegado a formar parte de la colectividad que gusta del entretenimiento a bajo costo: la difusión a través de las cadenas nacionales de televisión y sus programas de música popular en donde los videos de cada grupo, novel o con experiencia en la rama, venden la idea de una vida distinta a la que el espectador común está acostumbrado. ¿Será que ello le permite a la audiencia deslizarse por la realidad a través de la ficción?

En la región noreste de México impera la necesidad de ostentar, es decir, existe una tendencia a trasladar como deseables las acciones que grupos criminales llevan a cabo para denotar poder, estatus y control. Se presencia el ir y venir de camionetas de lujo conducidas por jóvenes que de la noche a la mañana son poderosos. Enriquecimiento sorpresivo y la ostentación de ropa y artículos de marca. Tienen un rasgo común: el tipo de música que escuchan. Son las canciones de banda ${ }^{2}$ que están de moda en la radio, son el hit musical del momento y los videos correspondientes se proyectan en las pantallas de los vehículos. La composición del video musical, con todo lo que ello implica: un guion, actores; (algunos simplemente los mismos vocalistas de tal agrupación, un tanto pasados de peso y en escenas de cama; actrices (mayormente mujeres en poca ropa) y realizadores con una historia para contar, inciden en la mente del receptor para inculcarle el deseo de tener, de pertenecer, de controlar. En fin, entre esta transición de la ficción a la realidad, "se muestran, individuos reducidos a 'cosas' de las que se puede disponer a placer" (Marzano, 2010, p. 10). Estos estímulos musicales en la comunicación verbal se constituyen en significativos para el sector social al que se dirigen, nos es útil la postura de Sperber y Wilson (2004) quienes enuncian que:

\footnotetext{
${ }^{1}$ Al hablar de "personajes" e "interpretación" en este trabajo, nos referimos también a la puesta en escena de las letras estudiadas, a los videos que acompañan las interpretaciones y que materializan, en ocasiones los contenidos que se cantan.

${ }^{2}$ Se llaman así, genéricamente, en México a las interpretaciones de grupos musicales compuesto de entre 8 y 15 músicos y cantantes.
} 
[...] el hablante puede transmitir una gama muy amplia de significados, a pesar de que no haya un nivel básico de información identificable de modo independiente que el oyente pueda captar. Lo que hace posible que el oyente reconozca la intención informativa del hablante es que las emisiones codifican formas lógicas (representaciones conceptuales, aunque sean fragmentarias o incompletas) que el hablante ha elegido de modo manifiesto para suministrarlas como input de los procesos de comprensión inferencial del oyente (Sperber y Wilson, 2004, pp. 250251).

\subsection{Articulación teórico-metodológica}

Desde una perspectiva interdisciplinaria describimos la manera en que se construyen los imaginarios discursivos (Pechêux, 1970) por medio de la letra de las canciones de banda, así como en la historia que se desarrolla en cada canción y en el video correspondiente, en donde los y las protagonistas muestran su deseo de conseguir posicionamiento social, poder, posesiones, un modo de vida apreciado en el entorno social, un habitus (Bourdieu, 2002) y, sobre todo, reconocimiento ante un grupo de iguales. Mostramos los recursos enunciados que los protagonistas de las historias contadas en las letras, e interpretadas en los videos, emplearon para obtener tales anhelos. En las letras de las composiciones se construyen las imágenes sociales (Goffman, 1971), desde los marcos de referencia construidos (Goffman, 2006) se proyecta la cosificación de la mujer y se crean representaciones sociales $^{3}$ (Moscovici, 1984; Jodelet, 1984; Van Dijk y Mendizábal, 1999) y socio discursivas (Charaudeau, 2011) asimétricas; se ejerce la violencia simbólica (Bourdieu, 2000), y verbal (Kaul De Marlangeon, 2006), y se genera el sexismo lingüístico (García Meseguer, 1994, 1998) entre las representaciones sociodiscursivas que se edifican sobre los personajes de la anécdota o historia que constituye las letras. Y a partir de ese proceso se construyen identidades masculinas de poder y femeninas subalternas (Lagarde, 1990) desde el discurso.

Tales desarrollos discursivos se realizan en la consideración de que hay una audiencia, un tercero, estudiado por Kerbrat-Orechionni y Plantin (en Denis, 1995), y por Charaudeau (2009b), que demanda esos contenidos; ese tercero, es el público fanático a esos grupos musicales. El éxito de estas agrupaciones, de los grupos que interpretan la música de banda, radica precisamente en que recurren a estos temas (el sexismo) y recursos (la construcción de representaciones asimétricas de los personajes, los temas relativos al poder económico y social, a la exaltación de la vida disipada), en los cuales se modelizan para el auditorio las perspectivas fáciles para obtener poder, para lograr posicionamiento social, y las acciones que se deben realizar para llegar a tales objetivos, porque, como enuncia Reig (2004) "dentro de ese comportamiento se encuentra la necesidad, todavía, del mito, del sueño, de aquello que les permita proyectar lo que ellos [los receptores] quisieran ser" ( $\mathrm{p}$. 246). Como se verá en la discusión de este trabajo.

\subsection{Corpus y estrategia metodológica}

Este trabajo se basa en una investigación cualitativa sobre un corpus de quince canciones populares mexicanas ${ }^{4}$ y sus respectivos videos; extrajimos cinco

\footnotetext{
${ }^{3}$ Hemos integrado estos conceptos: los marcos de referencia y la imagen social para definir operativamente el concepto de representación en este trabajo. Los autores (Goffman, 1971, 2006 y Pêcheux, 1970) lo proponen como un conocimiento social, colectivo, basado en creencias que le permiten al individuo comprender la realidad social. Charaudeau (2011) integra estas aportaciones y enuncia que se efectúan, se realizan a partir del discurso.

${ }^{4}$ Las canciones del corpus, por su tipología son: 5 boleros y 10 son canciones de banda.
} 
canciones y sus videos para configurar la muestra que analizamos: La revancha y Mi padrino el diablo (Benítez y Castro S/f), tocadas por la banda "La trakalosa de Monterrey"; Y ahora resulta (Alma Rosario, S/f), que interpreta el grupo "Voz de mando"; Mi último deseo y Hasta que salga el sol (Rubén Esli Castellanos. S/f) interpretada por el grupo "Los Recoditos". En el conteo, la muestra de las letras de canciones arrojó un total de 1146 palabras que fueron examinadas para el logro del propósito del trabajo. Segmentamos las letras de cada una de las canciones tomando como unidad operativa el acto de habla (Austin 1963); consideramos para el análisis las estrategias pragmáticas, retóricas y sociopragmáticas que aparecieron en la muestra; después con apoyo en las asociaciones semánticas (Saussure, 1945, pp. 151-153) articulamos las connotaciones del sentido de los vocablos que integran los actos de habla, luego contamos, organizamos e interpretamos los resultados para, en la dimensión discursiva elaborar hipótesis sobre los efectos sociales relativos a las actitudes, a la proyección del poder y a las imágenes edificadas. Ofrecemos luego los resultados, con base en las posturas teóricas declaradas líneas arriba.

Analizamos, desde la intencionalidad y la relevancia (Sperber y Wilson, 1994), algunas estrategias discursivas del sexismo (Glick y Fiske, 1996), la coerción y deslegitimación (Chilton y Schäfner, 2008) y la construcción de estereotipos ${ }^{5}$ (Calleja y Gómez Peresmitré, 2001) que, vinculadas a las emociones (Charaudeau, 2009a, 2011), desarrollan los diferentes enunciadores a partir de las letras y videos de canciones de banda del norte de México, que se divulgan en los medios. Nos es muy útil el aporte integrador que Amossy (2011) realiza del ethos partir de la revisión de este concepto desde una perspectiva interdisciplinar; la autora articula la retórica, la pragmática y la sociología en la construcción de su postura teórica:

El análisis pragmático presentado ofrece, en su propio terreno, un estudio fundado en la noción de intercambio; esta examina las instancias que contribuyen a la constitución de la interacción verbal en tanto tal. También analiza el locutor y la manera en que al participar en una interlocución construye una imagen de sí. Un análisis del ethos discursivo se integra, así, a un estudio de la interlocución que toma en cuenta los participantes, el escenario y los objetivos de intercambio verbal (Amossy, 2011, p.3).

De esta manera, en congruencia con las ideas de la autora:

Así, el ethos de los pragmáticos, en la línea de Aristóteles, se construye en la interacción verbal y es puramente interno al discurso, en tanto el de los sociólogos se inscribe en un intercambio simbólico regulado por mecanismos sociales y por posiciones sociales exteriores. Me propongo retomar esos dos enfoques para mostrar cómo, en una perspectiva abierta por la retórica, pueden ser complementarios (Amossy, 2011, p. 14).

Ilustramos el diseño de la articulación teórico-metodológica para alcanzar el objetivo de este estudio en la figura 1:

Figura 1. Modelo operativo interdisciplinar sobre la construcción de los imaginarios en la muestra.

\footnotetext{
${ }^{5}$ Según Gómez y Peresmitré 2001, "En México el estereotipo femenino incluye características tales como 'frágil, débil, que cuida de sus hijos, amorosa, pura y bonita' pero también

son frecuentes los adjetivos 'peligrosa', 'manipuladora', 'mentirosa', y 'agresiva" (citado en Palacios y Rodríguez, 2011: 12).
} 


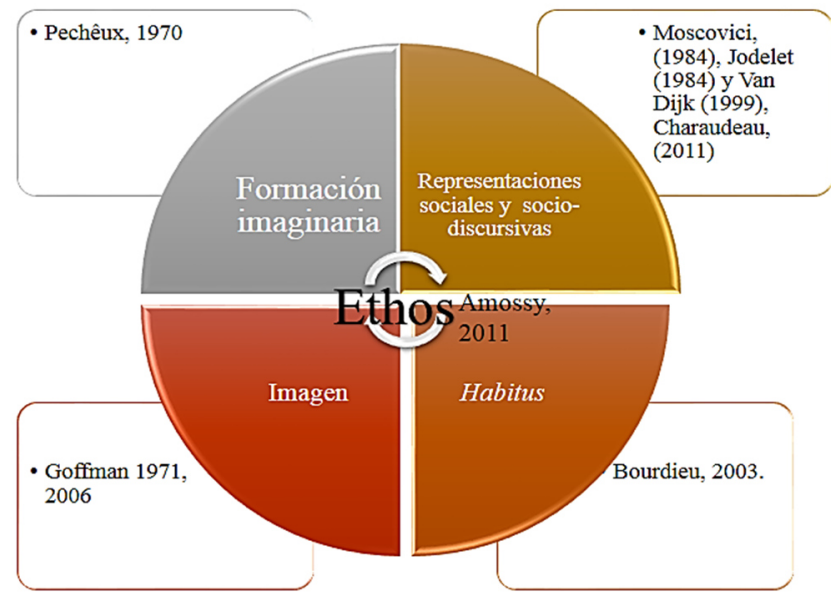

Fuente: elaboración propia.

\section{Discusión}

\subsection{Violencia, sexismo, representación y discurso}

La violencia produce un efecto social que busca dañar la imagen del sujeto referido en la comunicación: "por ejemplo, el insulto, la ridiculización, el empequeñecimiento, la usurpación de la palabra, es decir, todos aquellos actos que atentan contra la dignidad de la persona" (Fuentes y Alcaide 2008, p. 18). También resulta pertinente aplicar la postura de Bourdieu (2002) respecto al habitus o la socialización de los cuerpos, que explica la educación de las reacciones y la división psicológica de lo masculino y lo femenino. El autor enuncia que tal proceso se orienta hacia una mitología justificadora, es decir, aquello que se concibe como natural de los géneros y que origina la violencia simbólica, Estas acciones se revisan desde las funciones estratégicas del discurso político (Chilton y Schäfner, 2008).

Por otra parte, el sexismo, de acuerdo con Cameron (en Moya y Expósito, 2001, p. 643) se concibe como una actitud prejuiciosa o como conducta discriminatoria basada en la suposición de inferioridad o diferencia de las mujeres como grupo. Los autores Glick y Fiske (1996) hablan de sexismo ambivalente, que es cuando coexisten actitudes tanto positivas como negativas hacia las mujeres; las actitudes negativas las denominan sexismo hostil, que es la manifestación tradicional del sexismo (Glick y Fiske, 1996, p. 1), esa postura se estudia en este trabajo. Ellos abordan también el sexismo benévolo. Discriminan tres dimensiones que constituyen este tipo de sexismo: 1) la distribución del poder: es el paternalismo; 2) la diferenciación de género (competitiva o complementaria) y 3 ) la sexualidad, que se refiere a que las mujeres o carecen, o poseen una poderosa sexualidad que las hace peligrosas para los hombres, y propone que las relaciones de pareja heterosexuales son esenciales para lograr la felicidad (Glick y Fiske, 1996). Nos interesa aquí la distinción de esta acepción de la del sexismo lingüístico (García Meseguer, 1994), el cual García Meseguer (2001) explica:

Un hablante incurre en sexismo lingüístico cuando emite un mensaje que, debido a su forma (es decir, debido a las palabras escogidas o al modo de enhebrarlas) y no a su fondo, resulta discriminatorio por razón de sexo. Por el contrario, cuando la 
discriminación se debe al fondo del mensaje y no a su forma, se incurre en sexismo social (García Meseguer, 2001, p. 20).

El autor hace alusión a la relación que existe entre ambas perspectivas y recomienda: "Sexismo social y sexismo lingüístico están relacionados entre sí pero no deben identificarse" (García Meseguer, 2001, p. 20). Igualmente considera dos tipos de sexismo lingüístico:

Hay dos formas de sexismo lingüístico, una léxica y otra sintáctica. Se incurre en sexismo léxico por razón de utilizar ciertas palabras que pueden identificarse aisladamente. Se incurre en sexismo sintáctico cuando la discriminación se debe a la forma de construir la frase y no al empleo de una cierta palabra aislada (García Meseguer, 2001, p. 20).

Otra arista del tema, la constituye la representación sociodiscursiva propuesta por Charaudeau (2009a), que está prevista desde los marcos de referencia, y además sesgada por el factor emocional, ideológico:

Si se definen las emociones como estados mentales intencionales que se apoyan en creencias, entonces se puede decir que esta noción se inscribe en una problemática de la representación. De manera general, la representación procede de un doble movimiento de simbolización y de auto-presentación. Es un movimiento de simbolización en el sentido en que arranca los objetos del mundo de su existencia objetal ( $\mathrm{sic}$ ) figurándolos mediante cualquier sistema semiológico como una imagen que está dada por el objeto mismo y que, sin embargo, no es ese objeto (es la definición misma del signo lingüístico) (Charaudeau, 2009a, p. 101).

Charaudeau (2011) resume el papel de las emociones en la construcción de estereotipos o representaciones en el discurso: "Las emociones se encuentran, entonces, en el origen de un "comportamiento" en tanto que se manifiestan mediante las disposiciones de un sujeto, pero al mismo tiempo están controladas (incluso, sancionadas) por las normas sociales que provienen de sus creencias" (2011, p. 102). Las ideas del autor son útiles para sustentar que las representaciones discursivas de las mujeres y los hombres que en la letra de las canciones se construyen, se originan y producen ciertos efectos con base en creencias y posturas ideológicas.

\section{La construcción discursiva de los imaginarios}

Al estudiar la edificación de la imagen en los discursos de las canciones de banda, abordamos su descripción desde distintas perspectivas: a) las actitudes que enaltecen en los personajes a partir de su letra y las imágenes sociales que generan, b) los haberes deseables que sustentan ese ámbito social que describen y c) las acciones que las letras encierran con respecto al referente y al público al que se dirigen.

\subsection{Las actitudes}

Una de las actitudes que se manifiestan en los protagonistas es la impotencia, derivada de la victimización y la situación de vulnerabilidad que constituyen la imagen del protagonista y que justifican el consecuente resentimiento que se genera, como mostramos en el ejemplo 1: 
1) En su cara le matan a sus dos hijos 6 a su esposa entre dos tipos la comienzan a golpear/preguntaron cosas que ellos no sabían/los matones se veían comenzaron a dudar/murmuraron que se habian equivocado/un error que luego caro/lo tendrían que pagar... (Benítez, J., Ortega M. S/f. La Revancha, Edwin Luna y la Trakalosa de Monterrey).

Las canciones se constituyen en una narración que lleva al auditorio a seguir las argumentaciones que se brindan, en este caso, "un error que luego caro/lo tendrían que pagar", es una frase que anuncia la siguiente actitud del personaje que se documenta en el ejemplo 2, la venganza:

2) El destino pronto le dio "La Revancha“/de los matones las caras nunca se pudo borrar/a los años cayeron los asesinos/como si un poder divino lo quisiera compensar... Una noche que los matones dormíanlél les arranco la vida ya no despertaron más (Benítez, J., Ortega M. S/f. La Revancha, Edwin Luna y la Trakalosa de Monterrey).

De esta manera, se muestra un personaje que se ha transformado de víctima a victimario, ejerciendo una violencia justificada y hasta propiciada: "como si un poder divino lo quisiera compensar".

También se hallan en este corpus otras condiciones desfavorables generadas por actitudes de terceros cuyas consecuencias sufren los personajes, como el abuso, la violencia familiar, el temor, el abandono, así se ve en los ejemplos 3, 4 y 5:

3) ... cuando estaba morro ${ }^{7} / \mathrm{me}$ crié como un perro me la rifé $e^{8}$ solo/mi padre un borracho que me maltrataba/mi madre por miedo/miraba y callaba (Benítez, J., Castro, M. S./f. Mi padrino El Diablo, Edwin Luna y la Trakalosa de Monterrey).

4) Agarré la calle y luego los vicios/nunca fui a la escuela no conocí un libro (Benítez, J., Castro, M. S./f. Mi padrino El Diablo, Edwin Luna y la Trakalosa de Monterrey).

5) Sobre las banquetas dormí muy seguido/ y algunos cartones me cubrían el frío/ Quedé bien drogado debajo de un puente (Benítez, J., Castro, M. S./f. Mi padrino El Diablo, Edwin Luna y la Trakalosa de Monterrey).

Como se observa, la voz poética se perfila como una víctima: un niño desatendido, maltratado y luego abandonado; sin educación y presa de las adicciones. Estas circunstancias, en el argumento de la composición, se orientan a justificar la consecuente mutación del protagonista, a quien luego se le presenta una oportunidad de revanchismo, brindada por nada menos que el Demonio (ej. 6):

6) Un compa de negro me tocó la frente/Dijo soy el Diablo/te espanté a la muerte (Benítez, J., Castro, M. S./f. Mi padrino El Diablo, Edwin Luna y la Trakalosa de Monterrey).

7) Me dijo no temas yo vengo a ayudarte/y una mejor vida voy a regalarte/Hoy vas a tener lo que siempre soñastela cambio de tu alma voy a apadrinarte (Benítez, J., Castro, M. S./f. Mi padrino El Diablo, Edwin Luna y la Trakalosa de Monterrey).

\footnotetext{
${ }^{6}$ Hemos puesto en negritas los enunciados destacados por su carga semántico-pragmática.

${ }^{7}$ En México, "morro" significa pequeño, de corta edad.

${ }^{8}$ Esta frase pertenece a un modismo mexicano: "rifársela", que significa "me enfrenté/afronté/luché".
} 
La alternativa ante el desamparo se presenta para el personaje, quien, a cambio de su alma, y de un giro total en su vida (ej. 7), verá alcanzados sus anhelos.

\subsection{Proyecciones de lo deseable: empoderamiento, haberes, placer}

Una de las constantes conceptuales en la muestra es la búsqueda del poder por los personajes. Por convenir a los propósitos de este trabajo, seguimos a Duverger (1970) en su definición de poder:

[...] el poder instituido en una sociedad es al mismo tiempo, siempre y en todas partes el instrumento de dominación de ciertas clases sobre otras, utilizadas por las primeras para su beneficio, con desventaja de las segundas y un medio para asegurar un cierto orden social, una cierta integración de todos los individuos de la comunidad, con miras al bien común. La proporción de uno y otro elemento varía según las épocas, las circunstancias y los países (Duverger, 1970, p. 17).

Por otra parte, la clase de empoderamiento que se presenta en la muestra es definido por Morales (2016, con apoyo en Zimmerman y Rappaport) desde la psicología comunitaria, en su dimensión grupal como aquel que supone:

[...] una doble mirada: una "hacia fuera" del grupo, que tiene que ver con la capacidad del grupo de incidir en el medio y alcanzar sus objetivos; y otra "hacia dentro" que tiene que ver con la capacidad del grupo de hacer crecer a sus miembros, es decir de promover y desarrollar el empoderamiento individual de los mismos (Morales, 2016, pp. 28-29).

El poder del sector social al que se refieren las letras se describe en los ejemplos 8 y 9 :

8) Me gustan los parties y las desveladas/Lunes a Domingo y toda la semana/Me la paso alegre y disfruto la vida/Y así seguiré hasta mi último día/Me gusta el desmadre, el ambiente me prende (Castellanos, R. S./f. Mi último deseo, Banda Los Recoditos.).

9) Aquí ando en Las Vegas con unas plebonas 9 /manejo un Ferrari/y visto a la moda/Si quieren saber en qué paro la historia/ahí marquen al iPhone se las cuento toda (Benítez, J., Castro, M. S./f. Mi padrino El Diablo, Edwin Luna-La trakalosa).

En el ejemplo 8, los versos describen las preferencias del protagonista "las parties y la desvelada", quien expresa la clase de placeres que cultiva, y reitera que disfruta de ellos cada día "Lunes a Domingo y toda la semana". En 9, el personaje se dedica al juego y la diversión, así lo connota el lugar en el que se sitúa ${ }^{10}$ igualmente alude a la compañía femenina, el auto de lujo, la indumentaria costosa y el teléfono de última generación. Todas, posesiones muy lejos del alcance del ciudadano común mexicano.

La letra de las canciones, así como los videos que las acompañan proyectan escenas e imágenes de personas cuyas posesiones se relacionan con el placer y la

\footnotetext{
9 Plebonas en el norte de México, es una flexión de "plebe" (muchacho, muchacha), así, quiere decir "muchachonas", el aumentativo, connota lo impactante de la apariencia de las chicas referidas.

${ }^{10}$ En América del Norte, es bien sabido que Las Vegas, ciudad del estado de Nevada en Estados Unidos (llamada también comúnmente "la ciudad del pecado"), se distingue por estar formada casi por casinos, cabarés y centros de diversión. Y también porque tales diversiones son de muy alto costo para los mexicanos.
} 
diversión; se construyen campos asociativos que los representan y van construyendo su identidad ficcional, presentamos un caso en el ejemplo 10:

10) Vamos a empezar la fiesta/ya llame unas morras/para que se vengan/también a mi compa/que pase a la tienda/y que llene la troca/de pisto y cerveza (Castellanos R. S./f.. Hasta que salga el sol. Banda Los Recoditos)

En la aplicación observamos cómo se alude a un ambiente festivo, con mujeres jóvenes (morras), con amigos (mi compa), con consumo de bebidas (que pase a la tienda ${ }^{11}$ ), también hay referencias al tipo de transporte (la troca ${ }^{12}$ ) y lo que se consume ( pisto $^{13}$ y cerveza).

\subsubsection{Estereotipos, haberes, adquisiciones}

La identidad femenina en la sociedad mexicana, según Lagarde (1990) se construye, percibe y representa de la siguiente manera:

La identidad de las mujeres es el conjunto de características sociales, corporales y subjetivas que las caracterizan de manera real y simbólica de acuerdo con la vida vivida. La experiencia particular está determinada por las condiciones de vida que incluyen, además, la perspectiva ideológica a partir de la cual cada mujer tiene conciencia de sí y del mundo, de los límites de su persona y de los límites de su conocimiento, de su sabiduría, y de los confines de su universo. Todos ellos son hechos a partir de los cuales y en los cuales las mujeres existen, devienen (Lagarde, 1990, p. 1).

En la muestra, entre los estereotipos diseñados para la representación sociodiscursiva de los personajes aludidos en las canciones, destaca la apariencia física, que, como ya se veía líneas arriba (ej. 9) es valorada entre otras posesiones, como en los ejemplos 11,12 y 13 .

11) Te compré ropa y bolsa de diseñador/Unos lentes con brillantes incrustados/Te puse pechos, te puse nalgas/ y una cintura dónde tú tenías llantas (Félix M. S./f. Y ahora resulta, Voz de mando).

12) Te compré más zapatos que para un ciempiés/Y pestañas largas, negras y rizadas/Nariz bonita, respingadita/Y pa' blanquear te aplicaron concha nácar (Félix M. S./f. Y ahora resulta, Voz de mando).

13) Fuiste una mala inversión y me arrepiento (...) Maldita puta, antes de mi tú no eras nada! (Félix M. S./f. Y ahora resulta, Voz de mando).

Se observa la enumeración de los accesorios y atributos que constituyen el modelo de belleza mexicana a que se alude. En (11) incluso se mencionan los atributos de la persona gracias a la cirugía plástica; en (12) los rasgos y el tono de piel. Mientras que en (13) se ha nominado a la mujer referida como un objeto: una inversión- que no redundó ganancias.

La violencia verbal y el sexismo léxico se ejercen sobre la fémina referida a través de la hipérbole "más zapatos que para un ciempiés" (11); la imagen visual

\footnotetext{
11 "Pasar a la tienda" significa regionalmente, el ir a lugar donde venden las bebidas, los cigarros y lo que se consume en las reuniones.

${ }^{12}$ Es un término que se deriva de la adaptación al español del norte de México, del anglicismo the truck. Un vehículo generalmente costoso para la población, pero que usa el sector social representado en las letras de las canciones.

${ }^{13}$ Así se llama al conjunto de bebidas alcohólicas.
} 
"donde tú tenías llantas" (11); el desplazamiento de sentido por identidad de función "mala inversión" (13); la descripción de actitudes "me arrepiento"; hay degradación por medio de adjetivación "Maldita puta" (13); asimismo el sexismo sintáctico: uso copulativo en el segmento consecuencial: "antes de mí eras nada" (13). Respecto a este tipo de sexismo, García Meseguer (2001) apunta: "El sexismo sintáctico es más importante y significativo que el léxico, pues revela en quienes incurren en él un arraigo más profundo de la mentalidad patriarcal que yace en el fondo de sus subconscientes" (García Meseguer, 200, p. 21). La acumulación de recursos antes expuesta deviene en un acto de descortesía de fustigación, por refractariedad, con propósito lesivo de la imagen referida (Kaul de Marlangeon, 2006).

\section{Las representaciones socio-discursivas y las funciones del discurso}

Aprovechamos algunas de las categorías de Chilton y Schäffner (2008) que nos permiten examinar el discurso en estudio a través de las funciones estratégicas del discurso político de legitimación y deslegitimación, ya que en las canciones se legitima un modo de vida y se arguye sobre la conveniencia de vivirla con intensidad, véanse los ejemplos 14 a 16:

14) Yo así soy feliz, no le temo a la muerte/Yo no pienso en eso, es tiempo perdido/ Pues nadie se escapa de nuestro destino/Por eso aprovecho de cada momento (Castellanos, R. S./f. Mi último deseo, Banda Los Recoditos).

15) Pues consciente estoy de que no soy eterno/Por eso la paso contento en la peda/Y de vez en cuando le entro a la loquera/La vida es prestada y hay que disfrutarla/Como más te guste y te pegue la gana /Porque la huesuda no tiene respeto/Se lleva de todo, agarra parejo (Castellanos, R. S./f. Mi último deseo, Banda Los Recoditos).

16) Antes de meterme en el agujero/No quiero que lloren, no quiero sus lágrimas/Lleven a mi entierro música de banda/Échenme loquera y una de Buchanan's/Por si hay otra vida/Seguir la parranda (Castellanos, R. S./f. Mi último deseo, Banda Los Recoditos).

En los fragmentos se ilustra cómo, por medio de reiteraciones, la voz poética alude a la fugacidad de la vida: "no le temo a la muerte", "nadie se escapa a nuestro destino" (14), "no soy eterno", "la vida es prestada" "la huesuda no tiene respeto", "se lleva todo, agarra parejo" (15). Y establecida la fragilidad de la existencia, esa fugacidad es argumento para legitimar la despreocupación, los excesos, la diversión: "yo no pienso en eso, es tiempo perdido", "por eso aprovecho cada momento" (14); "por eso la paso contento en la peda ${ }^{14 ", ~ " l e ~ e n t r o ~ a ~ l a ~ l o q u e r a " ~}{ }^{15 ",}$ "échenme loquera", "y una de Buchanan's" (16). Para finalmente, a través de una hipérbole, expresar su deseo de seguir la fiesta después de la muerte: "Antes de meterme en el agujero/no quiero que lloren, no quiero sus lágrimas" "Lleven a mi entierro música de banda/ por si hay otra vida, seguir la parranda" (16).

Existe otra función: la de apelación (Jakobson, 1984) manifiesta en la muestra, a través de la cual pareciera que se pretende dar ejemplo, invitar al modus vivendi que se legitima, mostramos dos casos:

\footnotetext{
${ }^{14}$ Así se le llama en México al estado de embriaguez, más o menos prolongado o intenso.

${ }^{15}$ Esta expresión se refiere al consumo de sustancias diversas, como las drogas.
} 
17) Hay que ponerse bien pedos/hay que echar desmadre/y andar bien contentos/ponernos bien locos/sin quedarse arriba/nomás un poquito/pa cargar las pilas... (Castellanos, R. S./f. Hasta que salga el sol, Banda Los Recoditos).

18) Y que empiece la fiesta/y que empiece el desmadre/que toque la banda/canciones de arranque/vamos a entrarle a todo/y que nadie se me agüite/quiero escuchar suspiros/ver caras felices... (Castellanos, R. S./f. Hasta que salga el sol, Banda Los Recoditos).

En el ejemplo (17), hay una frase con valor distributivo "Hay que" que precede a la enumeración de acciones que conformarían el estilo de vida que se valida: "ponerse bien pedos/echar desmadre ${ }^{16} /$ andar bien contentos/ponernos bien locos"; así como partículas que sirven para intensificar el efecto perlocutivo deseado: "bien" (que hemos destacado en cursivas).En (18), la misma función la cumple el segmento "Y que" que antecede a los factores que constituyen la acepción de la diversión que se exalta: "empiece la fiesta/empiece el desmadre/toque la banda/entrarle a todo/nadie se me agüite/escuchar suspiros/ver caras felices".

\section{Resultados}

Exponemos los resultados obtenidos después de revisar en la muestra las funciones, presencia y frecuencia de vocablos asociados a los otros términos que su sentido convoca, se trata de hiperónimos ${ }^{17}$ que se edifican en las letras revisadas. Se proyecta un empoderamiento varonil, mostramos sus elementos en la Gráfica 1:

Gráfica 1. Rasgos del empoderamiento

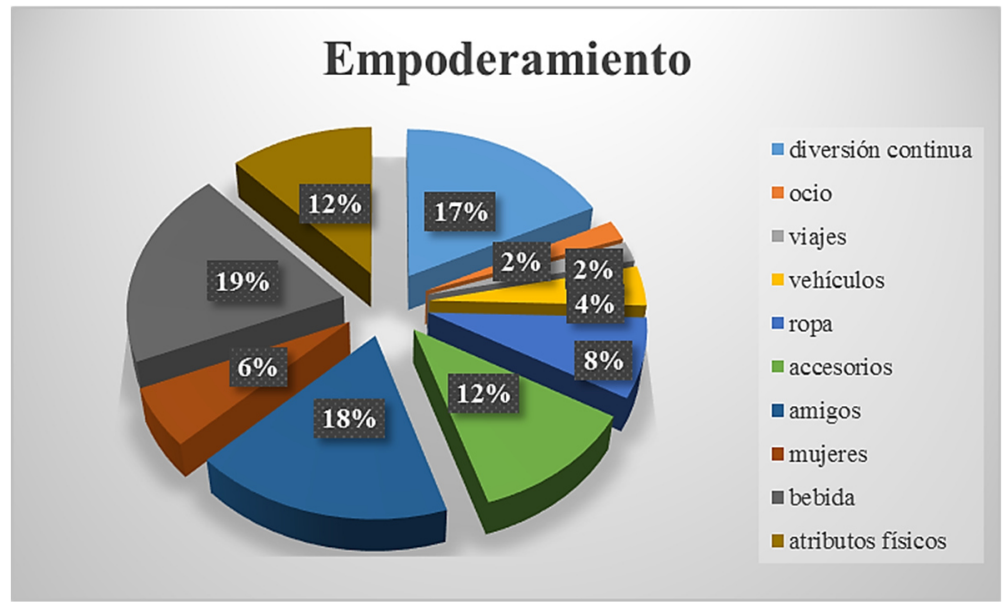

El vivir una fiesta perenne (17\%), embriagarse (19\%), poseer riqueza (viajes $2 \%$, vehículos $2 \%$, ropa $8 \%$, ocio $2 \%$ ), mujeres $(6 \%)$, grupos de amigos $(18 \%)$, buen aspecto $(12 \%)$, representa poder en la muestra.

La imagen masculina se integra por ciertos atributos que ilustramos en la Gráfica 2:

Gráfica 2. Imagen del varón

\footnotetext{
16 "Desmadre" en el contexto mexicano significa "desorden", “caos".

17 "Un hiperónimo designa aquel término general que puede ser utilizado para referirse a la realidad nombrada por un término más particular. Los hiperónimos, entonces, son palabras cuyo significado incluye o engloba el de otra u otras palabras" (PROLEE, 2011).
} 


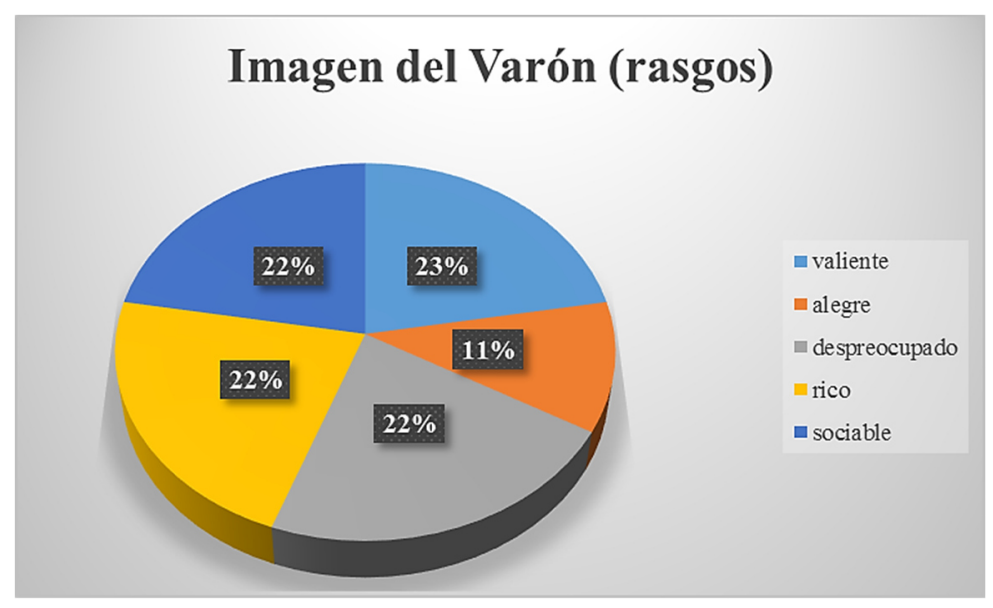

La identidad masculina es construida como superior a la de las féminas (a ellas solo se les reconocen atributos físicos), a partir de su valor (23\%) la posesión de bienes económicos materiales (22\%), numerosos amigos y mujeres (22\%), del disfrute de la vida (22\%) y conducta disipada (11\%).

En la Gráfica 3, ilustramos el estereotipo que constituye el canon popular de "la belleza femenina":

Gráfica 3. Imagen de la mujer

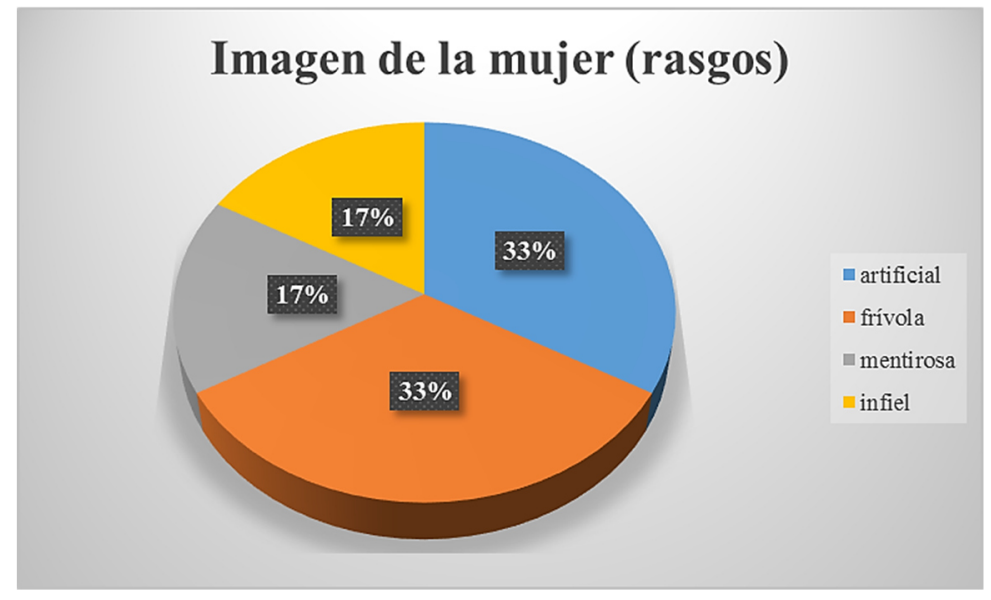

Se reproduce una imagen relacionada con atributos corporales artificiales (33\%), gusto por joyas, ropa (33\%); y tales representaciones son empleadas para manifestar prejuicios sobre las actitudes atribuidas a la identidad femenina: engaño (17\%), promiscuidad (17\%).

Se divulgan y actitudes como impotencia (12\%) abandono (25\%) y maltrato $(25 \%)$, y se ensalza la venganza (38\%).

\section{Conclusiones}

Los temas, el léxico y los ambientes abordados en las letras de las canciones de banda, corresponden al contexto socio-geográfico y a la ideología de cierto sector de la sociedad mexicana. De esta manera, a través de las composiciones y videos de este género musical, los pre-construidos socioculturales y los marcos de referencia que hemos descrito, se condiciona el predominio de un ethos (Amossy, 2016) deseable para los receptores de las canciones ya que se alude a la riqueza rápida, adquirida por medios distintos al trabajo. Se exalta un estilo de vida festivo hasta 
el extremo; existe una reiteración sobre la fugacidad de la existencia y, por consecuencia, la necesidad de vivir sin límites. La vida es una fiesta, y aún se celebra la muerte; se proponen como haberes deseables las posesiones materiales, económicas y aquellas valoradas socialmente en el entorno mexicano, como la accesibilidad a las mujeres y la dominación; todas ellas propuestas como maneras de empoderamiento social que brindan felicidad.

\section{Referencias}

1. Amossy, R. (2011) El ethos en la intersección de las disciplinas: retórica, pragmática, sociología de campos. Traducción de "O ethos na intersecção das disciplinas: retórica, pragmática, sociologia dos campos". En Ruth, Amossy (Org.). Imagens de si no discurso: A construção do ethos, São Paulo: Contexto, pp. 119-144. (Traducción: Pablo Pellejero).

2. Amossy, R. (Org.) (2016). Imagens de Si no Discurso: a construção do ethos. São Paulo: Contexto.

3. Astruells, S. (2012). Las bandas de música: desde sus orígenes hasta nuestros días. Melómano digital. Recuperado de:

https://www.melomanodigital.com/las-bandas-de-musica-desde-susorigenes-hasta-nuestros-dias/

4. Austin, J. (1963). Cómo hacer cosas con palabras. Barcelona: Paidós.

5. Bolívar, A. (2003). Análisis del discurso y compromiso social. Revista Akademus, 5, pp. 17-31. https://doi.org/10.19130/iifl.ti.2020.5.1.0003

6. Bourdieu, P. (2000). La dominación masculina. Barcelona: Anagrama.

7. Bourdieu, P. (2002). El habitus y los espacios de los estilos de vida. En La distinción. Criterio y bases sociales del gusto (pp. 169-222). México: Aguilar/Altea/Taurus/Alfaguara.

8. Calleja, N. y Gómez-Peresmitré, G. (2001). Psicología social. Investigación y aplicaciones en México. México: F.C.E.

9. Charaudeau, P. (2009a) Análisis del discurso e interdisciplinariedad en las ciencias humanas y sociales. En Puig, L. (Ed.), El discurso y sus espejos (pp. 99-133). México: Universidad Nacional Autónoma de México.

10. Charaudeau, P. (2009b). Tercero ¿dónde estás? A propósito del tercero en el discurso. En Montes, R. y Charaudeau, P. (Coords.). El "tercero" Fondo y figura de las personas del discurso (pp. 17-44). Puebla: Benemérita Universidad Autónoma de Puebla.

11. Charaudeau, P. (2011). Las emociones como efectos de discurso. Versión. La experiencia emocional y sus razones, 26, pp. 97-118.

12. Chilton, P. y Shäffner, C. (2008). Discurso y política. En Van Dijk, T. (Ed.) El discurso como interacción social (pp. 297-330). Barcelona: Gedisa.

13. Denis D. (1997). Reseña a Le Trilogue, dirigido por Kerbrat-Orecchioni, C y Plantin, C.. Lyon: Presses universitaires de Lyon (1995), L'Information Grammaticale, 73, pp. 61-62. Recuperado de:

http://www.persee.fr/doc/igram_02229838_1997_num_73_1_2934_t1_0061_0000_7

14. Duverger, M. (1970). Introducción a la política. Barcelona: Ariel

15. Fuentes Rodríguez, C. y Alcaide Lara, E. (2008). (Des)cortesía, agresividady violencia verbal en la sociedad actual. Sevilla: Universidad Internacional de Andalucía.

16. García Meseguer, Á. (1994). ¿Es sexista la lengua española? Una investigación sobre el género gramatical. Barcelona: Paidós.

17. García Meseguer, Á. (2001). ¿Es sexista la lengua española?. Panace@: Revista de Medicina, Lenguaje y Traducción, 2(3), pp. 20-34. Recuperado de: https://www.tremedica.org/wp- 
content/uploads/n3_GarciaMeseguer.pdf

18. Glick, P. y Fiske, S. T. (1996). The Ambivalent Sexism Inventory: Differentiating hostile and benevolent sexism. Journal of Personality and Social Psychology, 70(3), pp. 491-512. https://doi.org/10.1037/00223514.70.3.491

19. Goffman, E. (1971) La presentación de la persona en la vida cotidiana. Buenos Aires: Amorrortu.

20. Goffman, E. (2006). Frame analysis. Los marcos de la experiencia. Madrid: CIS/Siglo XXI de España

21. Jakobson, R. (1984). Lingüística y poética. Ensayos de lingüistica general (pp. 347-395). Barcelona: Ariel.

22. Jodelet, D. (1984): La representación social. Fenómenos, concepto y teoría, en Moscovici, S. (Ed.), Psicología social II. Psicología social y problemas sociales (pp. 469-494), Barcelona: Paidós.

23. Kaul de Marlangeon, S. (2006) Tipología del comportamiento verbal descortés en español. En Briz, A. et al. (Eds.) Cortesia y conversación. De lo escrito a lo oral. Actas del III Coloquio Internacional del Programa EDICE (pp. 254-266). Valencia: Departamento de Filología Española, Universitat de Valencia.

24. Lagarde, M. (1990). Identidad femenina. Recuperado de: http://poseidon.posgrado.unam.mx/publicaciones/ant_omnia/20/04.pdf

25. León, J. L. (1989). Persuasión de masas. Psicología y efectos de las comunicaciones sociopoliticas y comerciales. Madrid/Barcelona/Bilbao: Ediciones Deusto.

26. Marzano, M. (2010). La muerte como espectáculo. México: Tusquets

27. Mendoza, J. (2010). Poesía y género lírico. Acontecimientos posmodernos, por Alfonso Berardinelli. Crítica heterónima. Recuperado de: http://circulodepoesia.com/2010/12/poesia-y-genero-liricoacontecimientos-posmodernos-por-alfonso-berardinelli/

28. Morales, E. (2016). Empoderamiento y transformación de las relaciones de poder. Un análisis crítico de los procesos de participación ciudadana. Tesis doctoral. Doctorado en Políticas públicas y transformación social: Universitát Autónoma de Barcelona.

29. Moscovici S. (Ed.) (1984). Psicología social II. Psicología social y problemas sociales. Barcelona: Paidós.

30. Moya, M. y Expósito, F. (2001). Nuevas formas, viejos intereses. Neosexismo en varones Españoles. Psicothema, 13(4), pp. 643-649.

31. Pêcheux, M. (1978). Hacia el análisis automático del discurso. Madrid: Gredos.

32. PROLEE (2011). Hiperonimia. Administración Nacional de Educación Pública, Uruguay. Recuperado de: http://www.anep.edu.uy/prolee/index.php/glosario/49-hiperonimia

33. Reig, R. (2004). Dioses y diablos mediáticos. Barcelona: Urano.

34. Saussure, F. (1945). Curso de Lingüistica General. Buenos Aires: Losada.

35. Sperber, D y Wilson, D. (2004). La teoría de la relevancia. Revista de Investigación Lingüistica, 7, pp. 237-286. Recuperado de: https://digitum.um.es/jspui/bitstream/10201/17793/1/relevancia.pdf

36. Van Dijk, T. y Mendizábal, R. (1999). Análisis del Discurso social y Politico. Quito: ABYA-YALA. Recuperado de: http://digitalrepository.unm.edu/cgi/viewcontent.cgi?article=1414\&context =abya_yala 